\title{
INTELLIGENT CLOTHING WHIT PROGRAMMABILE INSULATION
}

\author{
First Rogale, S.; Rogale, D.; DragCEVIC, Z.; \\ NiKOLIC, G. \& BARTOS, M.
}

Abstract: An intelligent article of clothing is described, incorporating active thermal protection, which, in accordance with the outside environment temperature and microclimatic conditions within the article of clothing, vary thermal insulation properties of the clothing itself.

The algorithm of intelligent garment changes the value of thermal insulation, depending on the environmental temperature outside the garment and the microclimate inside the garment.

The actuator system of an article of clothing with thermal protection is a unit which adjusts the optimum level of the necessary thermal protection of an article of clothing. The system consists of a microcontroller assembly making decisions on activating the actuator, measuring amplifier and pressure sensors in the thermoinsulating chambers, air fill and release and compressed air microcompressor. All the elements make a complex actuator system which makes it possible to set a desired level of thermal insulation protection in an article of clothing

Key words: intelligent clothing, thermal protection, algorithm, actuator system
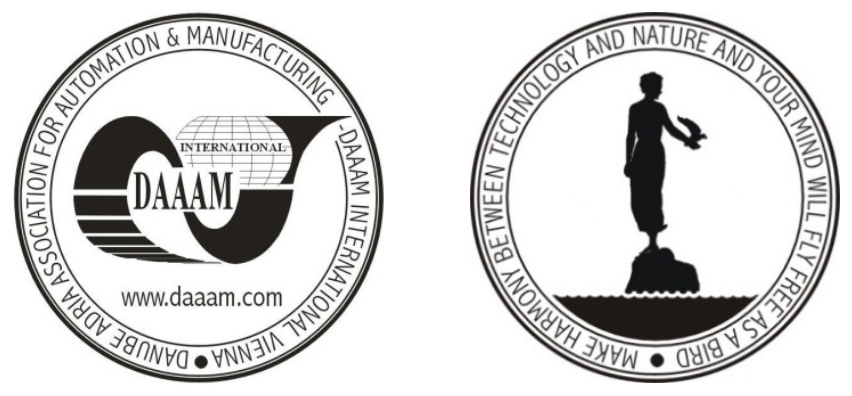

Authors' data: Dr. First Rogale, S[njezana]*; Rogale, D[ubravko]*; Dragcevic, Z[vonko]*; Prof. Nikolic, G[ojko]**; Prof. Bartos, M[ilivoj]***, *Faculty of Textile Technology, Sutlanska 16, 10000, Zagreb, HR, **Faculty of Textile technology, Jordanovac 119, 10000, Zagreb, HR, ***Pelcom d.o.o., Nehruov trg 5, 10020, Zagreb, HR, dubravko.rogale@ttf.hr, zvonko.dragcevic@ttf.hr, gojko.nikolic@ttf.hr, mic@pelcom.hr, sfrogale@ttt.hr

This Publication has to be referred as: First Rogale, S[njezana];Rogale, D[ubravko];Dragcevic, Z[vonko];Nikolic, G[ojko] \& Bartos, M[ilivoj] (2008). Intelligent Clothing whit Programmabile Insulation, Chapter 24 in DAAAM International Scientific Book 2008, pp. 273-286, B. Katalinic (Ed.), Published by DAAAM International, ISBN 978-3-901509-66-7, ISSN 1726-9687, Vienna, Austria

DOI: $10.2507 /$ daaam.scibook.2008.24 